\title{
Sculptured Surface Design and Implementation by Lofting Design Method Using Cross-sectional B-Spline Curves
}

\author{
Wisam Kadhum Hamdan* Mustafa Mohammed Abdulrazaq** \\ *, ** Department of Production Engineering and Metallurgy / University of Technology \\ *Email: wisamuot@yahoo.com \\ **Email: mustafaalneame@yahoo.com
}

(Received 8 March 2017; accepted 20 November 2017)

https://doi.org/10.22153/kej.2018.11.004

\begin{abstract}
This research presents a particular designing strategy for a free form of surfaces, constructed by the lofting design method. The regarded surfaces were created by sliding a B-spline curves (profile curves), in addition to describing an automatic procedure for selective identification of sampling points in reverse engineering applications using Coordinate Measurement Machine. Two models have been implemented from (Ureol material) to represent the different cases of B-spline types to clarify its scope of application. The interior data of the desired surfaces was designed by MATLAB software, which then were transformed to UG-NX9 software for connecting the sections that were designed in MATLAB program and obtaining G-code programs for the models In addition, a virtual machining process was simulated to show the machining pitfalls, using VERICUT software. The samples were machined using 3-axis vertical CNC machine (Isel) type.

Finally, the samples were measured using Faro arm (CMM inspection) and it was found that the average of errors was equal to $(0.0589 \mathrm{~mm})$ for the cross-sectional uniform B-spline model, and $(0.1337 \mathrm{~mm})$ for the lofted non-uniform B-spline model. It can be concluded that the whole steps task which built in the present research can be programmed in a single block of the part program where any surface at minimum designing time can be created from it.
\end{abstract}

Keywords: B-spline, CMM, , Lofted method, Sculptured Surface.

\section{Introduction}

The impact of globalization on business has forced most industries to become more innovative and implement newer strategies. In the aerospace automobiles, and many industry appliances, and different practical purposes sculptured surfaces are pertaining with designers and engineers to perform the required representation of the products. The milling of such complicated topologies is a main issue in CAM since the availability of $\mathrm{NC}$ machining, by their programs, to linear and circular movements [1,2]. Also, from reverse engineering which is a method utilized in the planning stage for a new products, can be depending on it to improve the design of any surfaces or it can be create a new surfaces depending on the original surface. Lofting is a modeling technique that fits a surface through a series of curves and builds the required topology for the resulting surface. Lofting can be used to create closed bodies as well as the open bodies [3]. The lofted surface is a two-parameter parametric function $\mathrm{S}(\mathrm{u}, \mathrm{v})$; the curves provide the $\mathrm{u}$ parameter of the surface and the lofting algorithm defines the $\mathrm{v}$ parameter [4]

The researchers' studies present a various methods in reverse engineering. Many of these studies are depend on the analyzing of points cloud gained by coordinates measuring equipment, like (CMM) Coordinates Measuring Machine, Optical Scanner or interferometry 
system. One of them was H. Park (2004) who introduced a novel method to fix the issue of interpolation the B-Spline surfaces to set of contours, by varying the numbers of points from contour to another. his method implies a new manner of obtaining a serial of coincident Bspline curves from the obtained contours. The method is depend on universal parameterization, that allows the knots to be taken freely but that gives the B-spline curve interpolation more linear system stability. Since the numbers of control point in the coincident B-spline curves equals to the largest numbers of contour point [5]. Ken Yano and Koichi Harada (2010) gave a new approach by skinning the generated cylindrical meshes for reconstructing B-spline surfaces. Their approach is usable only for generalizing cylindrical meshes, and there are numerous real objects which can be reconstructed and modeled by skinning the cylindrical meshes [6]. This research presents a particular designing strategy for a free form of surfaces, constructed by the lofting design method created by sliding B-spline curves.

\section{B-Spline Curves Modeling and Constructing}

A B-Spline curve differs from other modeling techniques such as Bezier or Hermite curve, where it generally consisting of more than one segment made up the curve. The segments are affected by only a few control points, which are the coefficient of B-Spline basis function polynomials. The curve degree is independent of the total number of control points. These characteristics allow changes in shape that do not propagate beyond one or only few local segments. The main formula that represents B-Spline curve in term of their blending functions is [7]:

$$
P(u)=\sum_{i=0}^{n} P_{i} N_{i, k}(u)
$$

Where $(\mathrm{Pi})$ is the control points and $(\mathrm{Ni}, \mathrm{k})$ representing the appropriate basis function for BSpline representation.

For B-Spline curves, the variable $(\mathrm{k})$ controls the degree of basis polynomial, which is independent of the numbers of control points. The basis function $(\mathrm{Ni}, \mathrm{k})$ is defined by following recursive equation [7]:

$N_{i, 1}(u)=1 \quad$ if $\quad t_{i} \leq u \leq t_{i+1}$

$$
=0 \quad \text { otherwise }
$$

And:

$$
N_{i, k}=\frac{\left(u-t_{i}\right) N_{i, k-1}(u)}{t_{i+k-1}-t_{i}}+\frac{\left(t_{i+k}-u\right) N_{i+1, k-1}(u)}{t_{i+k}-t_{i+1}}
$$

The (ti) represents the knot values, and a set of knot values comprises a knot vector $(\mathrm{T})$. The knot vector has a significant influence on the blending function $\mathrm{Ni}, \mathrm{k}(\mathrm{t})$ and theory on the B-Spline curve itself.

Since the knot vector values effecting on Bspline shapes, that classified B-Spline curves into periodic and non-periodic B-Spline curves [8].

\subsection{Uniform B-spline Curves}

Many geometric modeling situations do not require the curve to pass through the end points.

The uniform B-Spline curves is a piecewise polynomial curves controlled by a serial of points which the curves usually doesn't interpolates the end points. This method produces with a uniform or periodic knot vector, the basis functions repeating itself through successively interval for the parametric variables. The final equation of cubic periodic (uniform) B-spline curve when k4 is [9]:

$$
\begin{aligned}
& \mathrm{P}(\mathrm{u})=\mathrm{U} * \mathrm{MB} * \mathrm{P} \\
& P(u)=\frac{1}{6}\left[\begin{array}{llll}
u^{3} & u^{2} & u & 1
\end{array}\right]\left[\begin{array}{rrrr}
-1 & 3 & -3 & 1 \\
3 & -6 & 3 & 0 \\
-3 & 0 & 3 & 0 \\
1 & 4 & 1 & 0
\end{array}\right]\left[\begin{array}{c}
p_{0} \\
p_{1} \\
p_{2} \\
p_{3}
\end{array}\right]
\end{aligned}
$$

The initial data generated the required curves; the proposed programs represent the curves in a graphically with the help of MATLAB programming system. Figure (1) illustrates the designing of a single and series cubic B-Spline curves blended with each other to build the entire section of the closed B-spline curves.

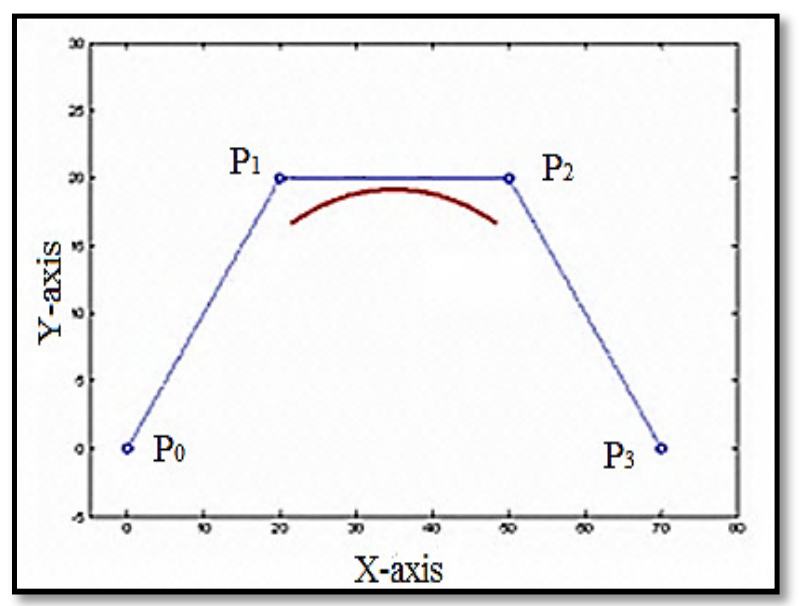

(a) 


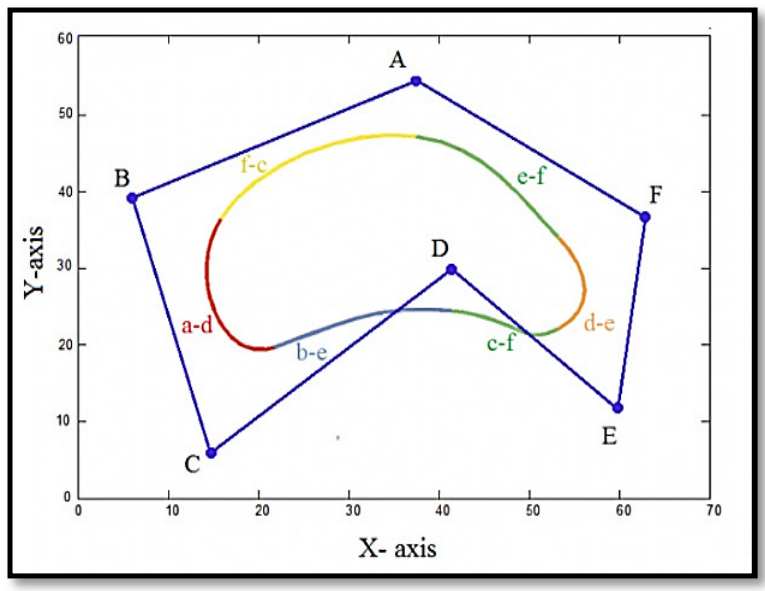

(b)

Fig. 1. Construction of uniform cubic curves: (a) single curve, (b) series of curves.

\subsection{Non-Uniform B-spline Curves}

Non uniform B-spline curve solves the problem of interpolating the curve with the vertices of control points, making it the preferred method in design, especially for the open parts where the uniform B-spline shows a deficiency in representation. The non-uniform B-spline curve consisting of number of segments depends on the value of the (n) and (k) variables in both directions of the vectors $(u, w)$. For a non-uniform B-Spline curve that interpolates the end points, the (ti) in eq. (3) is [10]:

$$
\left.\begin{array}{rlrl}
t_{i}=0 & \text { if } & i<k \\
t_{i}=i-k+1 & \text { if } & k \leq i \leq n \\
t_{i}=n-k+2 & \text { if } & i>n
\end{array}\right\}
$$

As a result of compensation the variables in eq.(3) The basis functions that generate multiple segments, each one is different from the other but complement each other.

For example the curve has two segments with $(\mathrm{n}=4, \mathrm{k}=4)$, and it has three segments with $(\mathrm{n}=5$, $k=4$ ). Figure (2) illustrates these cases of Nonuniform B-Spline curve.

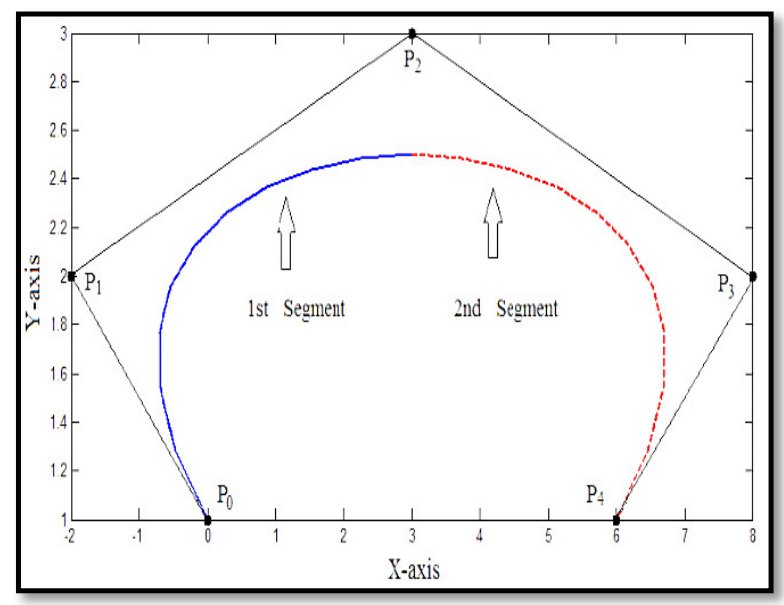

(a)

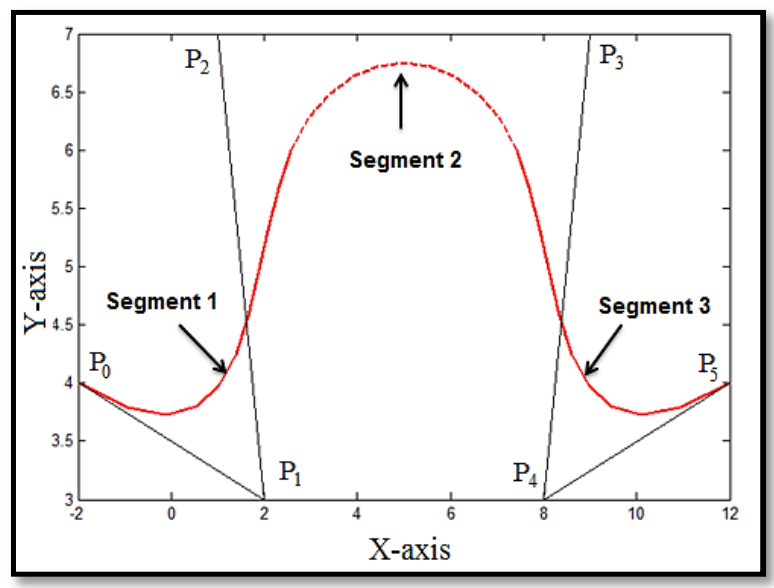

(b)

Fig. 2. Non uniform B-Spline curves, (a) $(n=4, k=4)$, (b) $(\mathrm{n}=5, \mathrm{k}=4)$

\section{Create the Sections of B-Spline Curves in The Proposed Work}

The lofting technique that used in the present work have been produced using the method of cross-sectional design concept. The models are generated through fits a surface through a series of curves and build the required topology for the resulting surface.

Two models have been designed to represent the different cases of B-spline types to clarify its scope of application. The first one created for representing the closed bodies using the Uniform $\mathrm{B}$-spline curves and the reason of that is the other type of B-spline curve (non-uniform) leads to generate a state of discontinuity at meeting the first and last points of polygon of control points, that's making the uniform B-spline curves as the preferred type for modeling such kinds of closed bodies. 
On the other hand the second model have been designed to representing the open bodies modeling using the Non-uniform B-spline curves because of the uniform type doesn't interpolate the end points of the control polygon which made a limitations in representation such surfaces like open profiles.

Generally both of the models had twoparameter parametric function $\mathrm{S}(\mathrm{u}, \mathrm{v})$; the curves provide the u parameter of the surface and the lofting algorithm defines the $\mathrm{v}$ parameter.

Using the programming language in Matlab program, curves are designed of different types of B-spline curves by building algorithms including the basis functions matrices for each type as illustrated in figure (3).

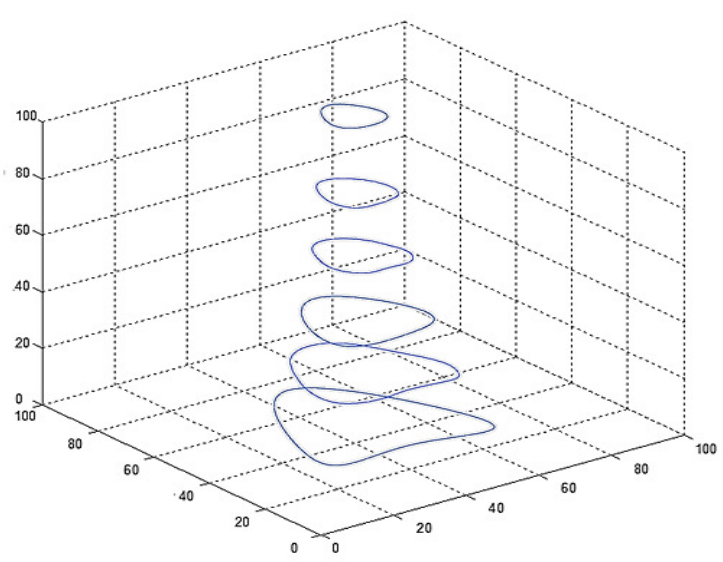

(a)

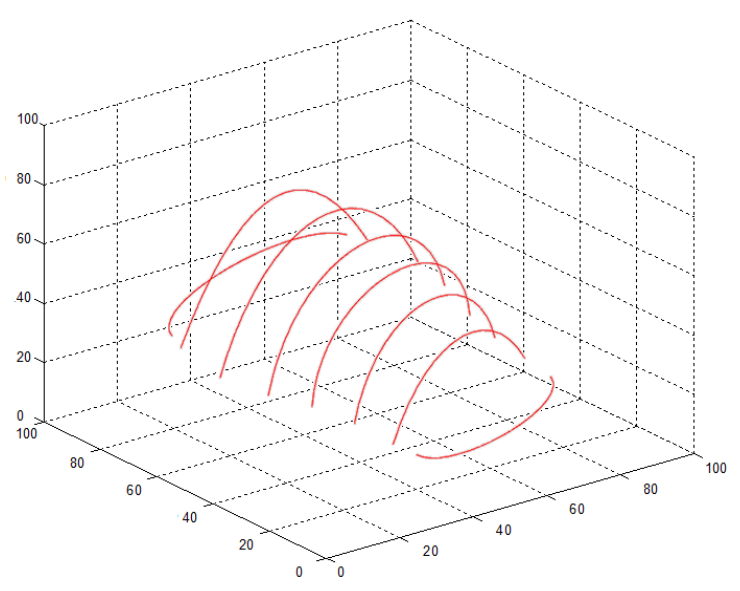

(b)

Fig. 3. The proposed sectional curves, (a) Closed uniform B-spline curves, (b) Open non-uniform Bspline curves

There are no any embedded functions in this software dedicated for the construction of the Bspline curves. Accordingly, special sub-routines have been implemented to construct the B-spline curves. Implementing the program to build the B- spline surface needs drawing the block diagram which is shown in figure (4).

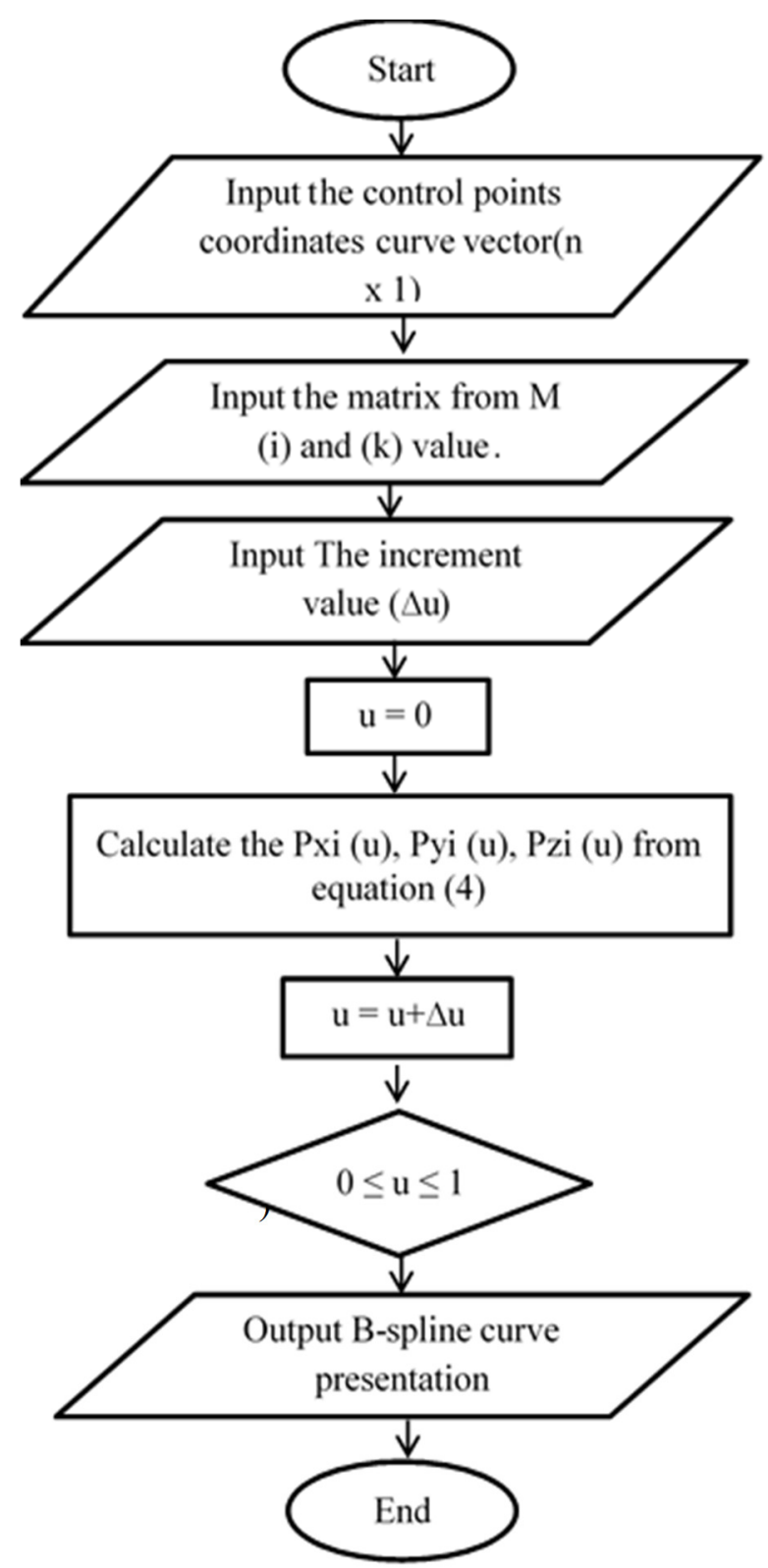

Fig. 4. Flowchart of the proposed program for building B-spline curve

\section{Skinning the sectional Curves and generating tool paths for the models}

The CAD module, where profile of the curves generating the surfaces which are modeled-using MATLAB, transferred to the UGS-NX9-through TXT data-exchanges file to view the required shape. After the construction of the B-spline curves, the data of each curve has been represented and saved in a single matrix of ( $\mathrm{nx}$ 3 ), where $n$ is the number of rows which is equal to $\mathrm{n}=1+\frac{1}{\Delta \mathrm{u}}$, where $\Delta \mathrm{u}$ is the increment of the 
independent parameter. Each matrix is saved as (txt) file and exported to the UG-NX program. Each imported curve has been opened individually in the UG-NX program. After importing each curve, a skinning procedure is to be followed converting these curves to a surface using the following steps.

\section{Insert urface $\rightarrow$ Mesh surface $\rightarrow$ Through curves}

Figure (5) illustrates the importing CAD data to UG-NX9 software after skinning the sectional curves for the both models.

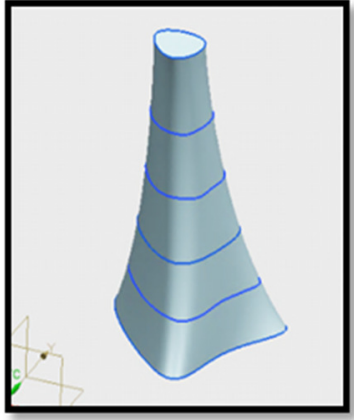

(a)

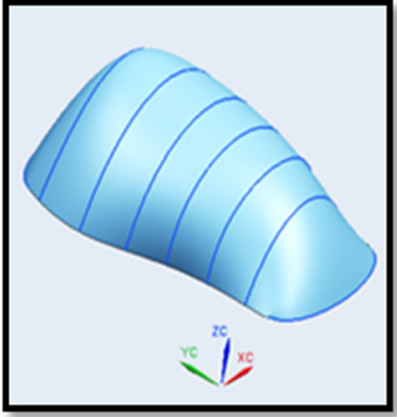

(b)
Fig. 5. Lofted surfaces after skinning, (a) Closed curves model (section of bone profile), (b) Open curves model (mouse profile).

\subsection{Tool Path Generation and Simulation Utilizing UG-NX}

After the completion of representing CAD models, it is followed by the process of generating the tool paths for designed part using UG-NX software. basing on the two phases of the process, the first phase is creating tool paths for the rough milling, where the characteristics must be chosen for this kind of machining, such as (Machining method, path strategies, tool shapes, tool diameters, feed rates ...etc.). The second phase is creating tool path for finish machining. In order to generate tool path for the models, flat-end tool with diameter $(8 \mathrm{~mm})$ have been used for rough machining. Since the aim of roughing is removing massy amounts of material, the value of step over in this stage will be higher than its value in finishing, which is approximately equal to five times of finishing step over value.

Figure (6) shows the two processes of machining for first model of the closed B-spline curves (section of bone profile), in addition to the second model that represents the lofted surface of open Non-uniform B-spline curves (mouse profile).

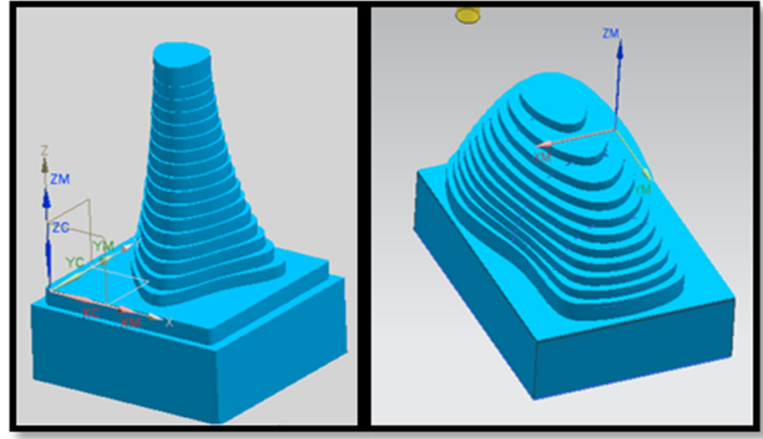

(a)

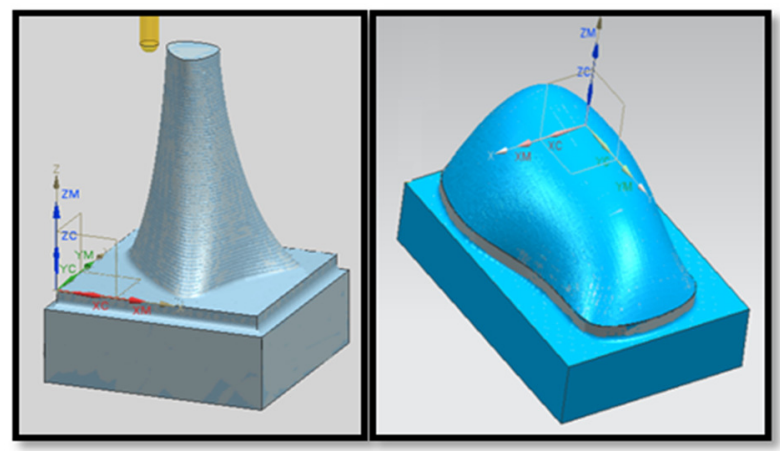

(b)

Fig. 6. Simulation of verifying tool path for the two models, (a) Rough machining, (b) Finishing process.

\subsection{Tool Path Verification}

The verification process has been done for the generated tool path using VERICUT software to detect the errors of $\mathrm{NC}$ program before loading the program on the CNC machine. G-code files imported to VERICUT software and a virtual machine has been designed to verify the tool path, and checking the machining pitfalls, as shown in figure (7).
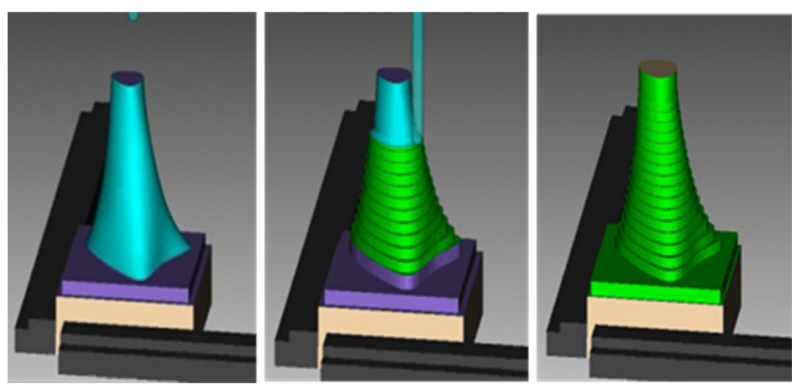

Fig. 7. Progress simulation of machining using VERICUT software 


\section{Experimental Work}

The machining process has been conducted on models from Ureol material, with different dimensions of the primary blocks as follows:-

1. Closed lofted model (uniform B-spline curves): $\mathrm{x}=50 \mathrm{~mm}, \mathrm{y}=50 \mathrm{~mm}, \mathrm{z}=75 \mathrm{~mm}$

2. Open lofted model (Non-uniform B-spline curves): $\mathrm{x}=80 \mathrm{~mm}, \mathrm{y}=100 \mathrm{~mm}, \mathrm{z}=80 \mathrm{~mm}$.

\subsection{CNC Milling Machine}

Milling processes have been performed on a vertical 3-axis CNC Milling machine "ISEL type" in the institute for machine elements, design and manufacturing in TU Bergakademie Freiberg in Germany, as illustrated in Figure (8). The characteristics are given in Table (1), to achieve the milling process for the models that have been designed.

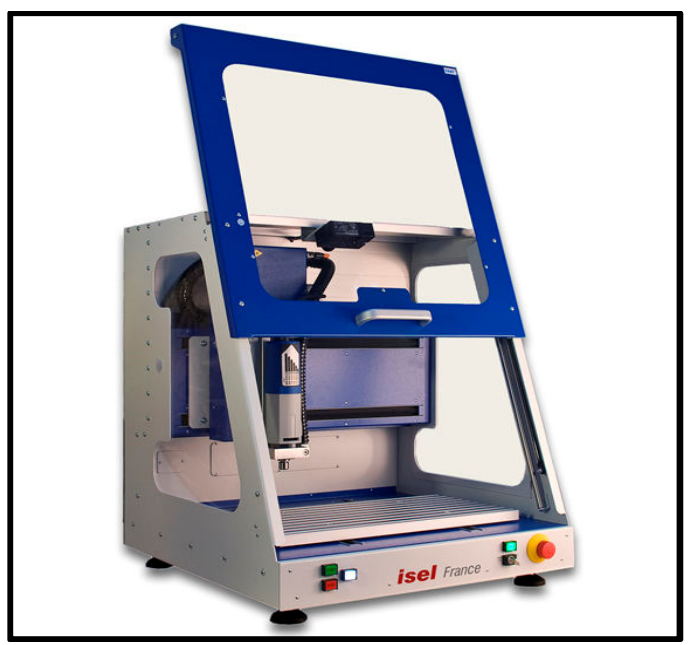

Fig. 8. 3-axis CNC machine (Isel type)

Table 1,

Characteristics of $\mathrm{CNC}$ milling machine

\begin{tabular}{|c|c|}
\hline \multicolumn{2}{|c|}{ Features of CNC milling machine ICP 4030} \\
\hline $\begin{array}{l}\text { Traverse path X/Y/Z } \\
\text { [mm] }\end{array}$ & $400 \times 300 \times 140$ \\
\hline $\begin{array}{l}\text { Software } \\
\text { Repeatability [mm] }\end{array}$ & $\begin{array}{l}\text { Pro NC } \\
\pm 0.02\end{array}$ \\
\hline Controller & $\begin{array}{l}500 \mathrm{~W} \text { power supply unit } \\
\text { with processor board }\end{array}$ \\
\hline $\begin{array}{l}\text { Process speed } \mathrm{X} / \mathrm{Y} / \mathrm{Z} \\
{[\mathrm{mm} / \mathrm{s}]}\end{array}$ & 100 \\
\hline Drive motors & Stepper motors \\
\hline $\begin{array}{l}\text { Dimensions } \mathrm{W} \times \mathrm{D} \times \\
\mathrm{H}[\mathrm{mm}]\end{array}$ & $780 \times 850 \times 810$ \\
\hline Throughput [bit/s] & 170 \\
\hline
\end{tabular}

\subsection{Machining Cutters}

Two kinds of milling tool are utilized in the proposed work research:

1- Flat-end mill tool with $(\varnothing 8 \mathrm{~mm})$ dia. and four flute cutters, made from (HSS) high-speed steel have been utilized for roughing.

2- Ball-end mill tool with $(\varnothing 8 \mathrm{~mm})$ dia. made from (HSS) for finishing. Fig.(9) shows the two types of cutting tools.

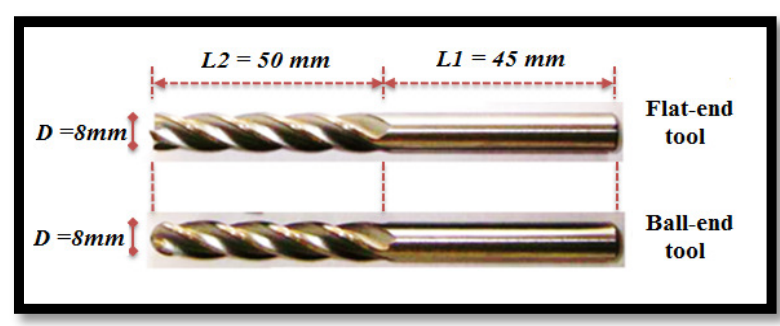

Fig. 9. Cutting tools used for machining

\subsection{Surface Machining}

The machining operations are executed in two processes; rough milling and finishing. Removing materials occurred in rapid way as much as possible during rough milling. The tool removed the materials in layers till the surface is encountered. Large amounts of material removal rate in rough machining are utilized to minimizing the process time. The rough milling occurred in parallel layers till access the required depths. The fineness of result surfaces in roughing is not significant as layers of material which left for finishing. Figure (10) shows the two passes roughing and finishing for machined the first part and figure (11) clarify the two phases for the second part.

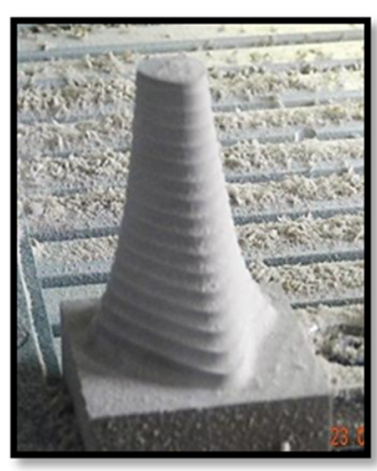

(a)

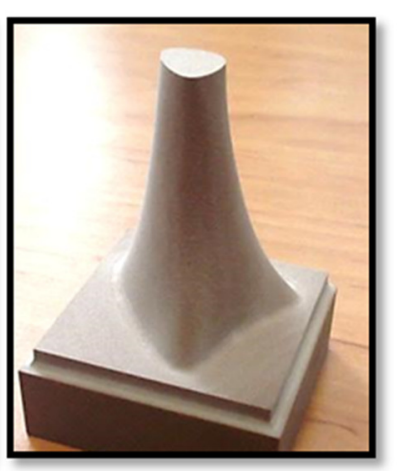

(b)
Fig. 10. Machining process for (section of bone profile), (a) Roughing, (b) Finishing 


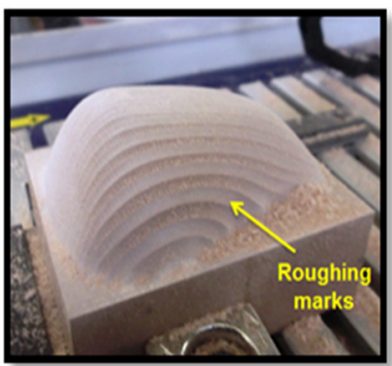

(a)

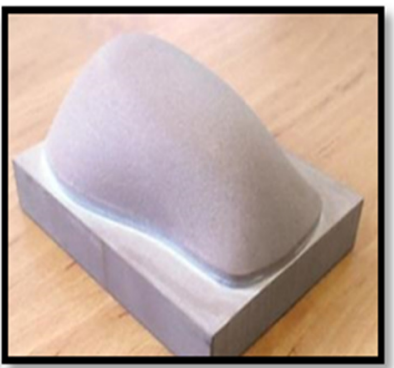

(b)
Fig. 11. Machining process for (mouse profile), (a) Roughing, (b) Finishing

\section{Measurement and Inspection}

The measurement process have been implemented using Faro-arm which is a portable $(\mathrm{CMM})$ coordinates measuring machine that gives an easy products verifications for the manufacturers to assessment the quality by making 3D inspection, CAD comparisons, dimensional analyzing, and reverse engineering. This arm consists of 6 degrees of freedom which facilitate the measurement process. Figure (12) shows the measuring arm.

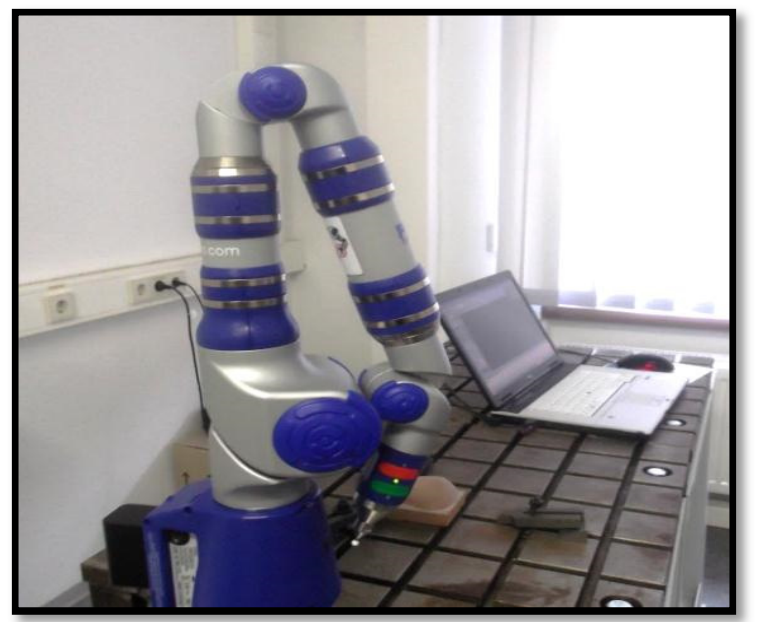

Fig. 12. Faro arm (CMM).

After machining, the measurement process has been conducted for the manufactured parts. The aim of testing these parts is to ensure that the product is manufactured with high precision, and to find out the differences between the CAD models which have been designed and the parts after the manufacturing process. Depending on the results of measuring, there will be evaluation of designing methods to see its feasibility success.

\subsection{Measurement of the Closed Lofted surface (Section of Bone)}

The measurement of each product (CAM model) can be conducted by scanning the entire products surface through passing the ball of the FARO arm over the whole surface. After measurements, the FARO CAM2 measure software imports design files in (IGES) format which contain the coordinate of each scanned points. Figure (13) illustrates the comparison process for the first model surface.

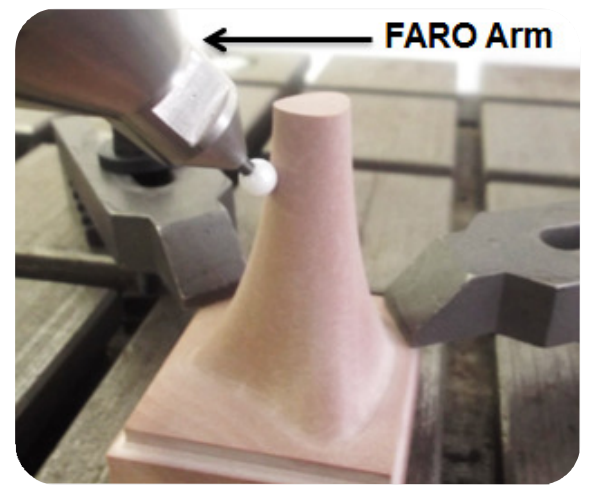

(a)
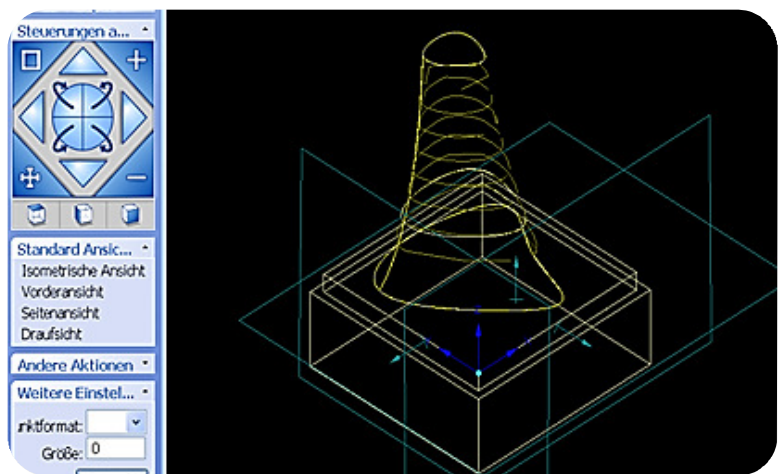

(b)

Fig. 13. Comparing between CAD and CAM models of the closed lofted surface, (a) CAD model in (FAROCAM2 software), (b) Scanning on real part.

After completion of measurement scheme, the program provides report, explains the details of the measurement and refers to the amount of error incident. Figure (2) shows a sample of measuring data for the first part. 


\begin{tabular}{|c|c|c|c|c|c|c|c|}
\hline \multicolumn{8}{|c|}{ M_FLÄCHE001.001 (Gemessen Scan über Schnittbereich.) } \\
\hline \multicolumn{2}{|r|}{ Ōbersichtsliste } & \multicolumn{2}{|c|}{27 Punkte } & \multicolumn{3}{|c|}{ O Punkte außerhalb Toleranz } & \\
\hline \multicolumn{2}{|r|}{ Durchschnitt: } & \multicolumn{2}{|c|}{$-0000,0544$} & \multicolumn{3}{|c|}{ Standardabweichung : } & 0000,0585 \\
\hline \multicolumn{2}{|r|}{ Min. Abstand : } & \multicolumn{2}{|c|}{$-0000,1407$} & \multicolumn{3}{|c|}{ Max. Abstand : } & 0000,0617 \\
\hline \multicolumn{2}{|c|}{ Gemessen } & Sollwert & Obere Tol & Untere Tol & Abw & Außerh. Tol & \\
\hline Länge & 0000,1407 & 0000,0000 & 0000,1500 & $-0000,1500$ & 0000,1407 & *newn & $\rightarrow$ \\
\hline \multicolumn{8}{|l|}{ Messergebnisse } \\
\hline ID & $\mathrm{x}$ & $Y$ & $z$ & Sollwert & Abstand & Außerh. Tol & \\
\hline 1 & 0027,8656 & 0010,9075 & 0008.5412 & N_FLACHEO01 & .0000 .0116 & ......... & \\
\hline 2 & 0027,2294 & 0010,5256 & 0008,4921 & N_FLACHEO01 & 0000,0151 & .......... & \\
\hline 3 & 0026.3550 & 0010,2806 & 0008.4959 & N_FLÁCHEO01 & 0000,0284 & ......... & \\
\hline 4 & 0029,0300 & 0012,0435 & 0008,7320 & N_FLÁCHE001 & $.0000,0252$ & ........ & \\
\hline 5 & 0030.4609 & 0014,4685 & 0009,0419 & N_FLACHEO01 & $-0000,0466$ & ......... & \\
\hline 6 & 0031.6691 & 0017.5110 & 0009.2432 & N_FLÅCHE001 & .0000 .0598 & ........ & \\
\hline 7 & 0032.1145 & 0018,8331 & 0009.2824 & N_FLÁCHE001 & $-0000,0602$ & ........ & \\
\hline 8 & 0032,6100 & 0020,3896 & 0009.2957 & N_FLACHEO01 & $-0000,0620$ & ........ & \\
\hline 9 & 0033.6295 & 0023,4633 & 0009.2178 & N_FLÅCHEO01 & -0000.0402 & ........ & \\
\hline 10 & 0033.9890 & 0024,5030 & 0009.1635 & N_FLÁCHE001 & $-0000,0372$ & ......... & \\
\hline 11 & 0035,3703 & 0029,0248 & 0008,7915 & N_FLÄCHEO01 & $-0000,0439$ & ........ & \\
\hline 12 & 0035,5649 & 0030,2523 & 0008,6665 & N_FLÄCHEO01 & $-0000,0571$ & (n....... & \\
\hline 13 & 0035,2942 & 0032,7453 & 0008,5097 & N_FLACCHEOO1 & $-0000,0829$ & ......... & \\
\hline 14 & 0031,5511 & 0035,7756 & 0008,9844 & N_FLÄCHEO01 & $-0000,1073$ & (n........ & \\
\hline 15 & 0030,0046 & 0036,2854 & 0009.0906 & N_FLÄCHEO01 & $-0000,1169$ & ........ & 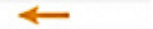 \\
\hline 16 & 0028,6416 & 0036,6350 & 0009,1438 & N_FLĂCHE001 & $-0000,1161$ & (n...m. & $\leftarrow$ \\
\hline 17 & 0025,0529 & 0037,2389 & 0009,1979 & N_FLÄCHEOO1 & $-0000,0991$ & ......... & \\
\hline 18 & 0023,9696 & 0037,3465 & 0009,2009 & N_FLACHEOO1 & $-0000,0908$ & ........ & \\
\hline 19 & 0017.5503 & 0037.1503 & 0009,1757 & N_FLACHEOO1 & $-0000,1364$ & .......... & $\leftarrow$ \\
\hline 20 & 0015,7362 & 0036,8392 & 0009,1619 & N_FLACHEO01 & $-0000,1335$ & (......... & $\leftarrow$ \\
\hline 21 & 0013,9018 & 0036,3437 & 0009,1436 & N_FLÁCHE001 & $-0000,1407$ & (n....... & $\leftarrow$ \\
\hline 22 & 0011,6982 & 0035,4467 & 0009,1099 & N_FLẢCHE001 & $-0000,1281$ & ........ & $\leftarrow$ \\
\hline 23 & 0008.2393 & 0031,7991 & 0009.0642 & NFLACHEOO1 & -0000.0447 & ........ & \\
\hline 24 & 0008,1261 & 0029,2156 & 0009,1727 & N_FLÁCHE001 & $-0000,0158$ & ........ & \\
\hline 25 & 0014,0628 & 0018,6232 & 0009,3463 & N_FLẢCHE001 & 0000,0352 & ....... & \\
\hline 26 & 0019,3629 & 0013,4887 & 0009,1617 & N_FLÄCHEOO1 & 0000,0473 & ........ & \\
\hline 27 & 0021,3444 & 0012,0195 & 0009,0183 & N_FLÄCHE001 & 0000,0617 & ........ & \\
\hline
\end{tabular}

Fig. 14. Sample of measuring data for the closed lofted part

In addition to the measuring data, it provides the values of some constants and variables such as the average of error and standard deviation.

Average of error $(\boldsymbol{\mu})=\frac{\sum x i}{n}$

Standard deviation $(\boldsymbol{\sigma})=\sqrt{\frac{\sum(x i+\mu)^{2}}{n}}$

Where: $\mathrm{xi}=$ error values, $\mathrm{n}=$ number of errors.

Table 2,

The average error, standard deviation and maximum error for the first model.

\begin{tabular}{lcc}
\hline The average error & 0.0589 & $\mathrm{~mm}$ \\
Standard deviation & 0.0713 & $\mathrm{~mm}$ \\
Maximum error & 0.1827 & $\mathrm{~mm}$ \\
\hline
\end{tabular}

\subsection{Measurement of Open Lofted surface}

Figure (15): shows the Comparison of CAD models and real part of the lofted surface, and figure (16) shows sample of measuring data for the second part (mouse profile).

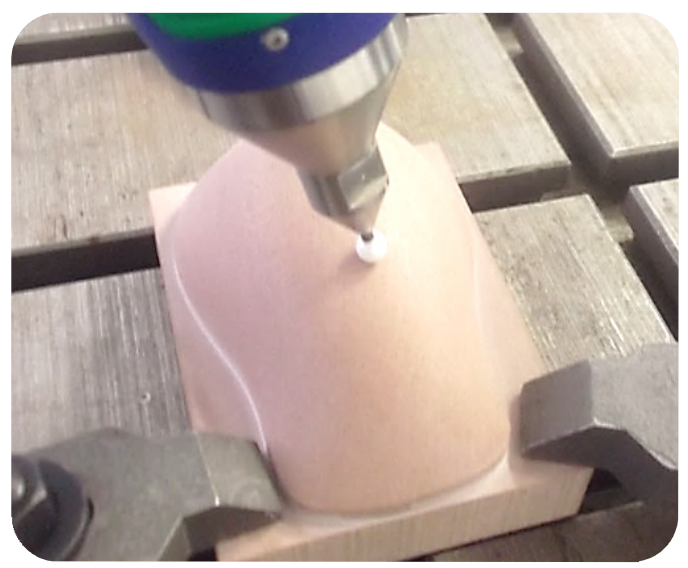

Fig. 15. Comparing between CAD and CAM models of the open lofted surface. 


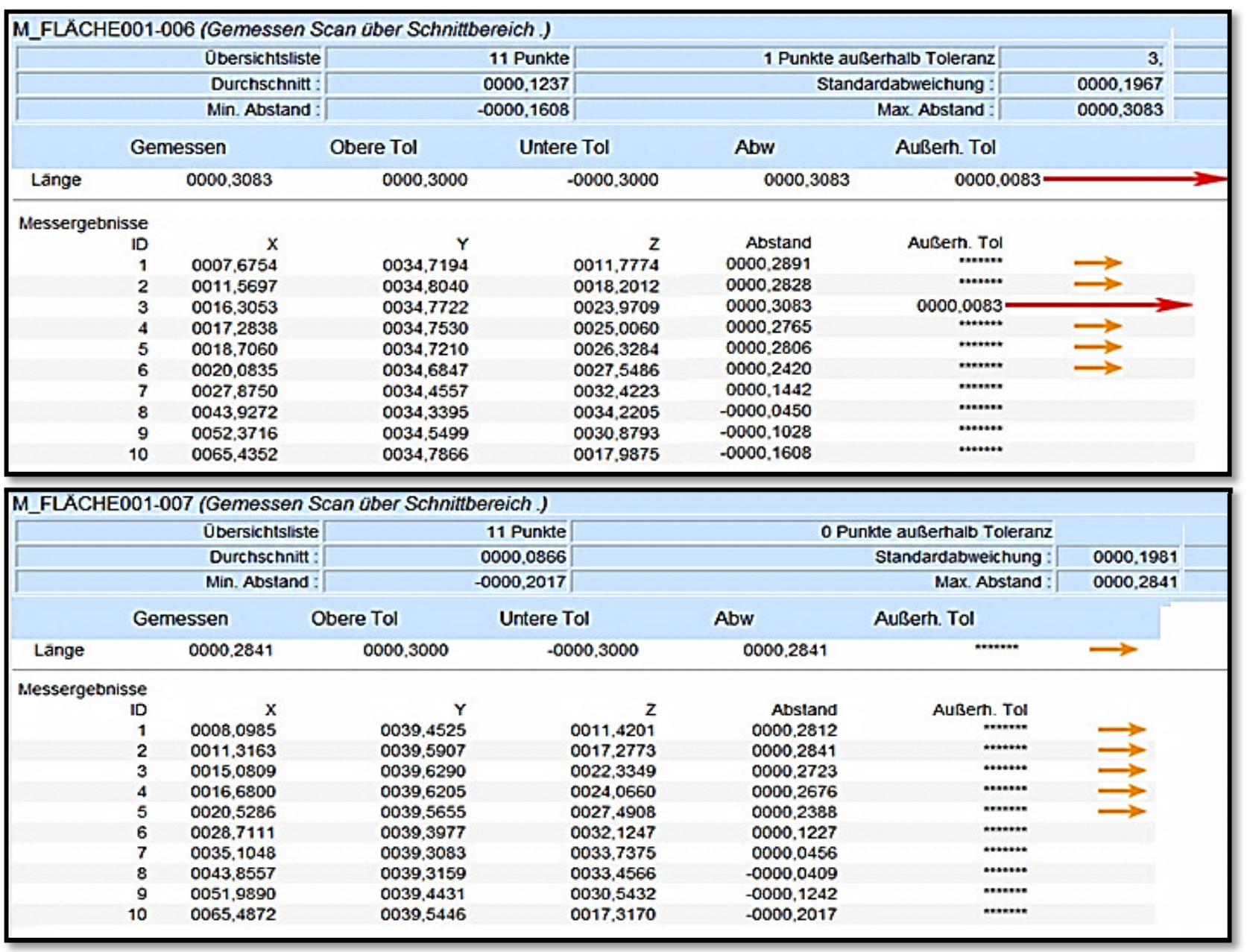

Fig. 16. Sample of measuring data for the open lofted part.

The big red arrow refers to exceeding the measured error to the given value of tolerance. On the other hand, the small yellow arrow refers to approach the value of measured error to the given tolerance.

Table 3,

The average error, standard deviation and maximum error for the open lofted surface.

\begin{tabular}{lll}
\hline The average error & 0.1337 & $\mathrm{~mm}$ \\
Standard deviation & 0.0414 & $\mathrm{~mm}$ \\
Maximum error & 0.1912 & $\mathrm{~mm}$ \\
\hline
\end{tabular}

\section{Conclusion}

- The design methodology of Lofted B-spline surface does not effect on the manufacturing result. The agreement for this concluding remark is the maximum produced error for closed B-spline model and the open lofted B- spline model are $(0.1827) \mathrm{mm}$ and $(0.1912) \mathrm{mm}$ respectively.

- The first segment of the non-uniform B-spline surface start with the polygon of control points, however it doesn't end with it, in opposite to the last segment which is end with the polygon of control points but it doesn't start with it.

- In spite of the limitation of interpolating the uniform B-spline curve with the polygon of control polygon, however it considered an advantage for representing the closed parts, because using the non-uniform B-spline curves leads to generate a state of discontinuity at meeting the first and last points of polygon of control points. Contrarily of representing the open parts which depends on the non-uniform type.

- The method has been implemented on various types of sculptured models. Looking at the given result, it is possible to say that this method has a good level of applicability in automated scansion systems 


\section{Reference}

[1]R. J. Yan, J. Wu, J. Y. Lee, C.-S Han“ A novel method for 3D reconstruction: Division and merging of overlapping B-spline surfaces, Computer-Aided Design, 2016.

[2] Sotiris, Andreas C., "A CNC machine tool interpolator for surfaces of cross-sectional design", Robotics and Computer-Integrated Manufacturing, 2006.

[3]H. Park, H. B. Jung, K. Kim "A new approach for lofted B-spline surface interpolation to serial contours" Int J Adv Manufacturing Technology 2004.

[4]K. R. Koch "Identity of simultaneous estimates of control points and of their estimates by the lofting method for NURBS surface fitting" The International Journal of Advanced Manufacturing Technology, 2009.

[5]H. Park, "An Approximate Lofting Approach for B-Spline Surface Fitting to Functional Surfaces" Int J Adv Manufacturing Technology 2001.
[6]Ken Yano \& Koichi Harada "Reconstruction of B-spline skinning surface from generalized cylinder mesh" The Visual Computer, Volume 26, No. 1, 2010.

[7]D. Auger, Q. Wang, J. Trevelyan, S. Huang \& Wei Zhao "Investigating the Quality Inspection Process of Offshore Wind Turbine Blades Using B-Spline Surfaces" Measurement, 2017.

[8]Y. Zhang, J. Cao, Z. Chen, X. Li \& X. Zeng," B-spline surface fitting with knot position optimization", Computers \& Graphics, 2016.

[9]Y. Yamaura, T. Nanya, H.Imoto \& T. Maekawa," Shape reconstruction from a normal map in terms of uniform bi-quadratic B-spline surfaces", Computers \& Graphics, 2015.

[10] Y. Zhang, J. Cao, Z. Chen, X. Li \& X. Zeng," B-Spline Curve Fitting with Invasive Weed Optimization", Applied Mathematical Modelling, 2017. 


\title{
تصـميم وتنفيذ الاسطح الحرة بأسـتخدام طريقة التصميم للمقاطع المستعرضة لمنحنيـات
} الـ

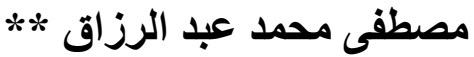

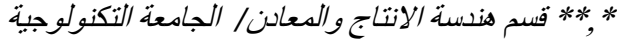 \\ * وسام كاظم حمدان \\ wisamuot@yahoo.com:البريد الالكتروني \\ mustafaalneame@yahoo.com البريد الالكتروني:**
}

هذا البحث يقدم استر اتيجية لتصميم الاسطح بشكل عملي، تتم بوساطة استخدام طريقة المنحنيات المستعرضة. الاسطح التي تم در استها تم تكوينها

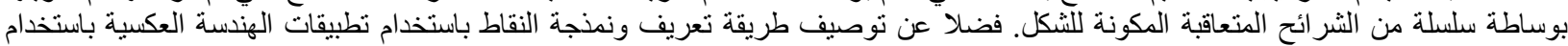

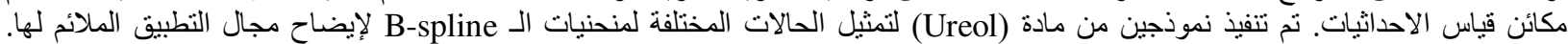

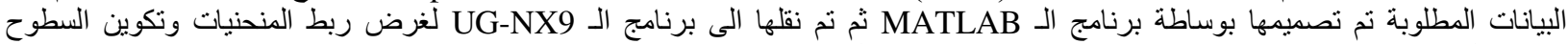

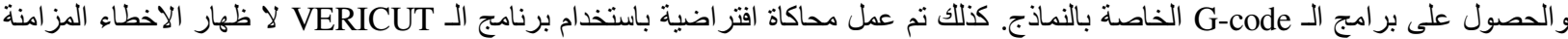

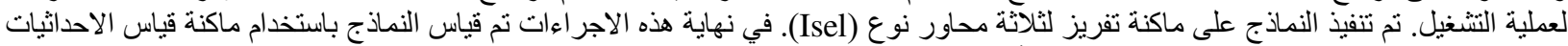

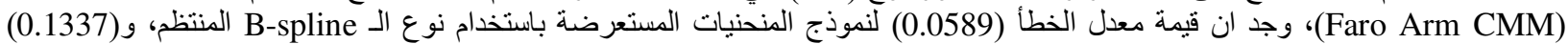

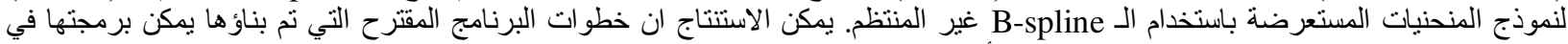
برنامج تصميمي و احد من هذا يمكننا تنفيذ اي سطح في أقصر وقئ وقت تصميمي. 